\title{
TACE/ADAM17 is involved in germ cell apoptosis during rat spermatogenesis
}

\author{
Carlos Lizama', Diego Rojas-Benítez ${ }^{1}$, Marcelo Antonelli², Andreas Ludwig ${ }^{3}$, \\ Ximena Bustamante-Marín ${ }^{1}$, Jurriaan Brouwer-Visser ${ }^{1}$ and Ricardo D Moreno ${ }^{1}$ \\ ${ }^{1}$ Departamento de Ciencias Fisiológicas, Facultad de Ciencias Biológicas, Pontificia Universidad Católica de Chile, \\ Alameda 340, 8331010 Santiago, Chile, ${ }^{2}$ Facultad de Medicina, ICBM, Universidad de Chile, 6640022 Santiago, \\ Chile and ${ }^{3}$ Institute for Pharmacology and Toxicology, RWTH Aachen University, D-52074 Aachen, Germany \\ Correspondence should be addressed to R D Moreno; Email: rmoreno@bio.puc.cl \\ C Lizama and D Rojas-Benítez contributed equally to this work
}

\begin{abstract}
The pathways leading to male germ cell apoptosis in vivo are poorly understood, but are highly relevant for the comprehension of sperm production regulation by the testis. In this work, we show the evidence of a mechanism where germ cell apoptosis is induced through the inactivation and shedding of the extracellular domain of KIT (c-kit) by the protease TACE/a disintegrin and metalloprotease 17 (ADAM17) during the first wave of spermatogenesis in the rat. We show that germ cells undergoing apoptosis lacked the extracellular domain of the $\mathrm{KIT}$ receptor. TACE/ADAM17, a membrane-bound metalloprotease, was highly expressed in germ cells undergoing apoptosis as well. On the contrary, cell surface presence of ADAM10, a closely related metalloprotease isoform, was not associated with apoptotic germ cells. Pharmacological inhibition of TACE/ADAM17, but not ADAM10, significantly prevented germ cell apoptosis in the male pubertal rat. Induction of TACE/ADAM17 by the phorbol-ester phorbol 12-myristate 13-acetate (PMA) induced germ cell apoptosis, which was prevented when an inhibitor of TACE/ADAM17 was present in the assay. Ex-vivo rat testis culture showed that PMA induced the cleavage of the KIT extracellular domain. Isolation of apoptotic germ cells showed that even though protein levels of TACE/ADAM17 were higher in apoptotic germ cells than in nonapoptotic cells, the contrary was observed for ADAM10. These results suggest that TACE/ADAM17 is one of the elements triggering physiological germ cell apoptosis during the first wave of spermatogenesis.
\end{abstract}

Reproduction (2010) 140 305-317

\section{Introduction}

Cell survival and apoptosis are tightly regulated by a myriad of signals to determine the faith of a cell. Inhibition of the survival signaling of tyrosine kinase receptors such as KIT (c-kit) tilts the balance toward apoptosis (BlumeJensen et al. 2000, Kissel et al. 2000, Yan et al. 2000, Bedell \& Mahakali Zama 2004). In the testis, an inactivating point mutation at the intracellular domain of KIT blocking the binding of phosphoinositide-3phosphate kinase induces germ cell apoptosis and leads to infertility (Blume-Jensen et al. 2000, Kissel et al. 2000). In addition, genetic evidence from the mouse testis suggests that inactivation of KIT signaling is linked to apoptosis mediated by the expression of FAS, a type I transmembrane receptor belonging to the tumor necrosis factor (TNF)/nerve growth factor receptor family (Sakata et al. 2003, Lizama et al. 2007). In humans, associations between polymorphisms in the KIT gene and idiopathic infertility have also been found (Galan et al. 2006). Even though the importance of KIT in male germ survival is well documented, it is unknown whether KIT inactivation forms part of the mechanism involved in physiological germ cell apoptosis. Even more, it is unknown whether in vivo processing of KIT leads to apoptosis.

Several type 1 surface receptors with a single transmembrane domain, including receptors for TNF and epidermal growth factor (EGF), can be physiologically blocked by proteolytic processing of their extracellular ligand-binding domain (Blobel 2005). A family of transmembrane metalloproteases known as 'a disintegrin and metalloprotease' (ADAM) proteins is a key component in protein ectodomain shedding (Huovila et al. 2005). ADAMs play a key role in diverse biological processes such as fertilization, myogenesis, neurogenesis, heart development, and endothelial permeability, mainly by regulating paracrine/juxtacrine cell-to-cell communication (Seals \& Courtneidge 2003, Blobel 2005). ADAMs are type 1 transmembrane proteins of $\sim 70-90 \mathrm{kDa}$ (mature proteins; the unprocessed precursors are about $20 \mathrm{kDa}$ heavier due to 
their prodomain). They feature a common modular ectodomain structure, encompassing (counting from the membrane) a variable stalk region; a cysteine-rich domain that can interact with cell surface proteoglycans and in some cases also contains a fusion peptide sequence; a disintegrin domain binding to integrinclass cell-adhesion molecules; a zinc-binding metalloprotease domain; and a prodomain that is cleaved off in the trans-Golgi network by protein convertases (Seals \& Courtneidge 2003, Blobel 2005). The TNF- $\alpha$ convertase (TACE or ADAM17) was the first member of this family, for which a role in ectodomain shedding was found. The role of TACE/ADAM17 in the shedding of tyrosine kinase receptors, such as the EGF receptor (EGFR), has been distinctively confirmed through the analysis of knockout mice (Blobel 2005). This type of evidence has indicated that TACE/ADAM17 can also process the ectodomain of several membrane-bound EGFR ligands such as neuregulin and EGF (Sahin et al. 2004). ADAM10 is another member of this family of proteases, which has been thoroughly studied since it has been shown to be involved in the shedding of key developmental regulatory proteins such as EGFR, NOTCH receptor, pro-TNF- $\alpha$, and the amyloid precursor protein (Huovila et al. 2005).

The most straightforward mode of ADAM action is the constitutive shedding of a membrane substrate by cleaving a site in its juxtamembrane region (Seals \& Courtneidge 2003, Blobel 2005). In a given cell type, certain ADAMs may participate in constitutive shedding while others in stimulated shedding; an example of the latter is the shedding of EGFR mediated by the phosphorylation of TACE/ADAM17 and induced by transforming growth factor- $\beta$ (Wang et al. 2008). In addition, ADAM 10 and TACE/ADAM 17 can be induced to shed different ligands when cells are treated with phorbol 12-myristate 13-acetate (PMA), suggesting a role for protein kinase $\mathrm{C}(\mathrm{PKC})$ in the activation of these enzymes (Huovila et al. 2005). Although ADAM1 and ADAM2 were first discovered in the testis and have relevance in fertilization, no further studies exist on the role of ADAMs and ectodomain processing by ADAMs 17 or 10 in testis physiology (Tousseyn et al. 2006). During spermatogenesis, a tight coordination of growth and differentiation exists, which is brought about by growth factors and cytokines produced and released by germ cells and Sertoli cells; the latter are somatic cells present within seminiferous tubules and are involved in the homeostasis of germ cells (Yan et al. 2000, Skinner 2005, Kassab et al. 2007, Perrard et al. 2007). Taken together, these precedents suggest that ADAM proteases could have an important role in controlling the processing and release of signaling molecules, and mammalian spermatogenesis provides an excellent model to study paracrine/juxtacrine signaling.

Spontaneous death of germ cells induced by both physiological and environmental signals is a wide spread, but little understood phenomenon that occurs in the testes of many species (Billig et al. 1995). Early after birth, the first round of spermatogenesis is characterized by a massive wave of apoptosis, which is believed to be fundamental for the establishment of a proper interaction between germ cells and sperm production (Billig et al. 1995, Jahnukainen et al. 2004, Moreno et al. 2006a, Zheng et al. 2006). It has been shown that this massive wave of apoptosis peaks at 25 days after birth in the rat, affecting mainly germ cells in meiosis (pachytene spermatocytes). These cells show caspase-8, -9, -3, -6, and -2 activation, along with an upregulation of FAS receptors and the transcription factor p53 (Lizama et al. 2007). However, the mechanisms inducing germ cell apoptosis are still unknown.

Signaling of the tyrosine kinase receptor KIT is fundamental for germ cell survival during mammalian spermatogenesis. The activated receptor becomes autophosphorylated at tyrosine residues that serve as docking sites for signal transduction molecules containing $\mathrm{SH} 2$ domains. KIT activates AKT, SRC family kinases, phosphatidylinositol 3-kinase, phospholipase- $\gamma$, and RAS/MAP kinases (Roskoski 2005). In vivo blocking of the interaction of KIT with its ligand stem cell factor (SCF), produced by the Sertoli cell, leads to a massive increase in germ cell apoptosis (Vincent et al. 1998, Yan et al. 2000). We hypothesized that during spermatogenesis, extracelullar domain shedding of KIT could lead to an impairment of its intracellular signaling promoting germ cell survival, which would promote apoptosis.

The aim of this work was to evaluate whether KIT extracellular domain shedding induced by TACE/ADAM17 is associated with germ cell apoptosis during the first wave of spermatogenesis in the rat.

\section{Results \\ TACE/ADAM17 is present in germ cell and participates in apoptosis}

Apoptosis is a well-known process but poorly understood process in mammalian spermatogenesis. To further elucidate this process, seminiferous tubules of 25-day-old rats were chosen because of the highest number of apoptotic cells observed at this age, the product of the massive wave of germ cell death during the first wave of spermatogenesis (Billig et al. 1995, Rodriguez et al. 1997, Jahnukainen et al. 2004, Moreno et al. 2006a, Codelia et al. 2008). To determine whether apoptotic cells posses the extracellular domain of KIT, we performed immunohistochemistry of paraffinembedded testis slides. The antibody ACK2, directed against the extracellular domain of KIT, labeled only $21 \pm 4 \%$ of apoptotic (pycnotic) cells (Fig. 1A, red arrowheads). On the contrary, an antibody directed against the intracellular domain of KIT labeled $81 \pm 4 \%$ of the apoptotic cells (Fig. 1B). Activation of KIT in the testis was assessed by immunohistochemistry using a 
phospho-specific antibody to detect phosphorylation of KIT at Tyr719, located in the intracellular kinase domain of the receptor. Interestingly, most of the apoptotic cells $(99 \pm 5 \%)$ did not show any staining when using an antibody against phopho-KIT (Fig. 1C).

Previously, we showed that germ cells undergoing apoptosis are characterized by an upregulation of FAS receptor levels, allowing separation (for details see Materials and Methods). Western blots of FAS (-) protein extract showed two bands of around $120-140 \mathrm{kDa}$, corresponding to the molecular weight of KIT (Fig. 1D). These two bands appear due to the presence of two different glycosylated isoforms of KIT (Ronnstrand 2004). FAS $(+)$ cells also showed these bands, although they were significantly less intense than in FAS $(-)$ cells (Fig. 1D and E). An additional band around $60 \mathrm{kDa}$ was
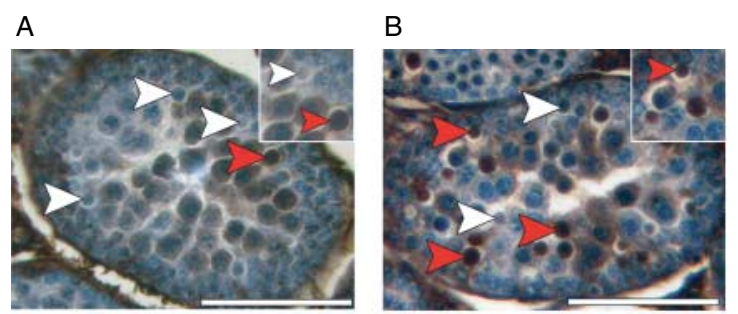

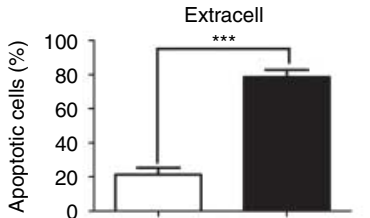

$(+)$
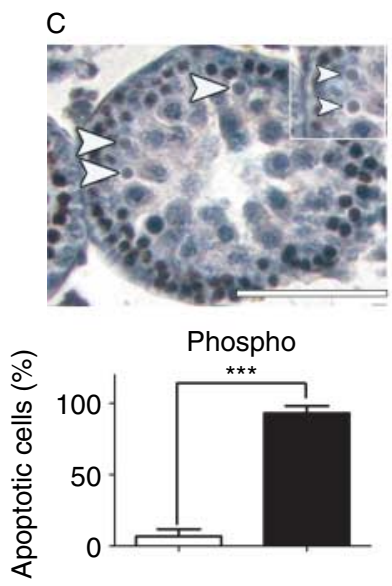

$\mathrm{E}$

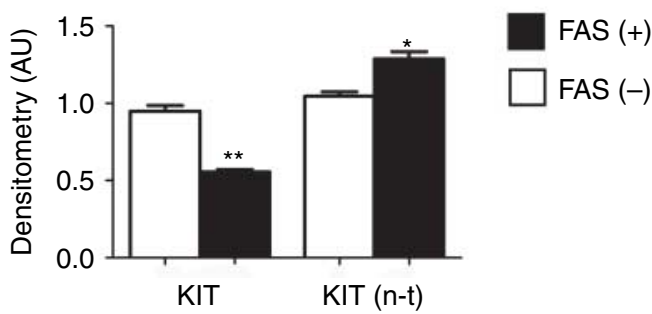

detected in FAS $(+)$ cells, which was significantly more intense than in FAS $(-)$ cells (Fig. 1D and E, KIT $(n-t)$ ). Since the antibody recognized the intracellular domain of KIT (N-terminal), we hypothesized that the $60-\mathrm{kDa}$ band is a fragment containing the intracellular and the transmembrane domain, which result from shedding of the extracellular domain of KIT in apoptotic germ cells. As an alternative procedure, we evaluated whether apoptotic cells, as determined by flow cytometry, were devoid of the extracellular domain of day-KIT. Results showed that in a cell suspension of a 25-old rat testis, almost $26 \%$ of cells were sub-G ${ }_{1}$ (apoptotic cells), and $56 \%$ were positive for KIT (Fig. $2 \mathrm{~A}$ and $\mathrm{B}$ ). When we analyzed only the sub- $\mathrm{G}_{1}$ cell population, we observed that a small fraction of these cells $(24 \pm 3 \%)$ had the extracellular domain of KIT (Fig. 2C and D). Mammalian testes have different cell populations with different amounts of DNA, among which are haploid spermatids. Since these cells only have half the amount of DNA of other cell types, we wondered whether they could account for the sub- $\mathrm{G}_{0}$ population observed in control animals. We isolated both pachytene (meiotic cells) and haploid spermatids, and analyzed them by flow cytometry. Results showed that purified pachytene cells presented a homogeneous population (see Supplementary Figure $1 \mathrm{~B}$, see section on supplementary data given at the end of this article). On the contrary, purified haploid cells showed a sharp single peak in a region different from sub- $\mathrm{G}_{1}$ cells (see Supplementary Figure 1C). Therefore, the events observed in 25-day-old rat cells indeed correspond to sub- $\mathrm{G}_{0}$ cells, probably both pachytene and spermatogonia in apoptosis. Next, we used confocal microscopy to determine whether TUNEL-positive cells

Figure 1 Apoptotic germ cells lack the extracellular KIT domain. (A) Immunohistochemistry against KIT using an antibody recognizing the extracellular domain of KIT (ACK2). Note that many spermatogonia and spermatocytes were heavily stained. Some pycnotic cell lacked this label (white arrowheads), but others show an intense brown color (red arrowheads). (B) Immunohistochemistry against the KIT intracellular domain shows that many spermatogonia and spermatocytes, as well as pycnotic (apoptotic) cells, were heavily stained with this antibody (red arrowheads). (C) Immunohistochemistry against the phosphorylated intracellular domain of KIT, staining was absence in pycnotic (apoptotic) cells (arrowheads). Bars $100 \mu \mathrm{m}$. The graphs represent the proportion of pycnotic cells presenting $(+)$ or not presenting $(-)$ staining against the extracellular or intracellular portion of KIT or phospho-KIT respectively. Values were determined by counting a total of 300 cells, for each antibody in three different rats. ${ }^{* * *} P<0.001$. (D) Apoptotic (FAS (+)) and nonapoptotic cells (FAS (-)) were isolated from 25-day-old rat seminiferous tubules, and the presence of KIT was analyzed by western blot. Full length KIT was found predominantly in FAS (-) cells. On the contrary, a processed form of KIT containing the intracellular (N-terminal) domain, KIT (n-t), was found predominantly in FAS (+) cells. Golgi protein of $160 \mathrm{kDa}(\mathrm{GP160})$ was used as a loading control. (E) Quantification of KIT (full-length protein) and the 60-kDa fragment (KIT (n-t)) in FAS (+) (black bars) and FAS $(-)$ (white bars) cells. Graphs show the intensity of each band relative to GP160 as a loading control. $n=3, * P<0.5$; ${ }^{* *} P<0.01$. 

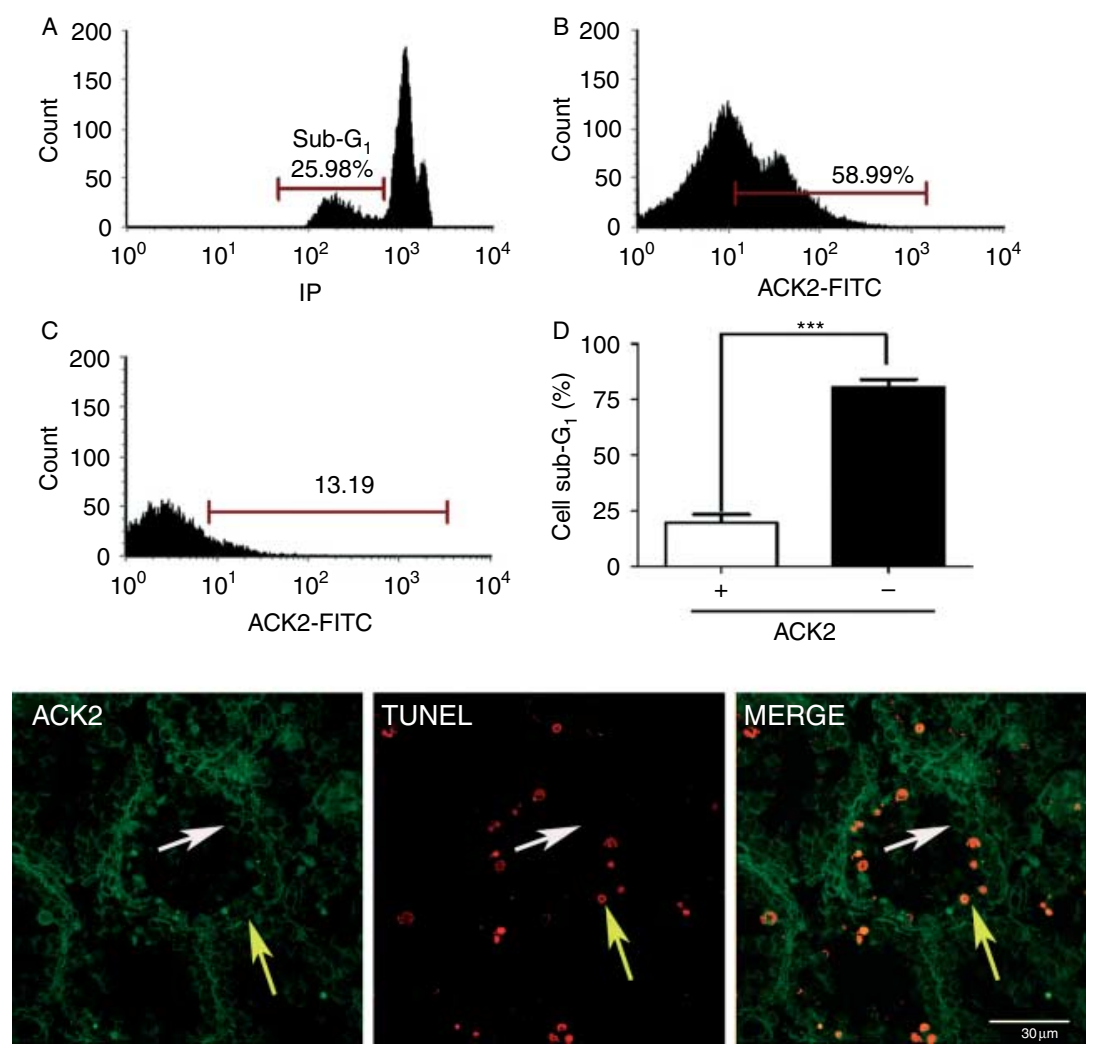

Figure 2 Apoptotic germ cells lack the extracellular domain of KIT. (A) Isolated cells from 25-day-old rats showed that almost $26 \%$ are in sub- $\mathrm{G}_{1}$, representing apoptotic cells. (B) The same cell population showed that almost $60 \%$ of the cells were labeled using the antibody that recognizes the extracellular domain of KIT. (C) When only apoptotic cells (sub-G ${ }_{1}$ ) are analyzed, only a small percentage was labeled for the extracellular domain of KIT. (D) Quantification of apoptotic cells (sub- $\mathrm{G}_{1}$ ) showing the presence $(+)$ or absence $(-$ ) of KIT extracellular domain as evaluated by ACK2 antibody binding, $n=3$, *** $P<0.001$. (E) Confocal microscopy of rat testes sections showing the localization of the extracellular domain of KIT (green, white arrows) and TUNEL (red) in the same section. Note that all KIT-positive cells lack TUNEL staining (yellow arrows).

lacked the extracellular domain. The antibody directed against the extracellular domain of KIT (ACK2) showed a green line denoting the cell surface of spermatogonia and spermatocytes (Fig. 2E, white arrow). On the other hand, TUNEL-positive cells (red spots) lacked KIT (Fig. 2E, yellow arrows). These results indicate that germ cells undergoing physiological apoptosis during the first wave of spermatogenesis lack the extracellular domain of KIT.

Extracellular proteases of the ADAM family are involved in the shedding of the extracellular domains of different transmembrane receptors. Furthermore, in cultured mast cells, TACE/ADAM17 has been reported to process KIT (Huovila et al. 2005). For this reason, we decided to investigate the role of TACE/ADAM17 and ADAM10 in germ cell apoptosis. The histology of 25-day-old rat testis showed mitotically dividing spermatogonia at the basal membrane and meiotic spermatocytes toward the lumen (Fig. 3A). Only a few seminiferous tubules showed haploid round spermatids, but elongating spermatids or spermatozoa will appear later in testis development. Immunohistochemistry for ADAM10 showed a cytoplasmic distribution in pachytene spermatocytes lining in the second and/or third tier in seminiferous tubules (Fig. 3A arrowheads). Immunohistochemistry for TACE/ADAM17 showed a faint homogeneous expression in all cells within the seminiferous tubules, as well as in Leydig cells (Fig. 3B). However, apoptotic (pycnotic) cells showed a strong labeling using this antibody (Fig. 3B', red arrows). Interestingly, most of the apoptotic cells, as evaluated by histology, were devoid of ADAM10 staining (Fig. 3A') while nonapoptotic spermatocytes in the contiguous tubule, or in the same tubule, were strongly stained. In fact, $83 \pm 11 \%$ of apoptotic cells lacked the expression of ADAM10 (Fig. 3C). On the contrary, most of the apoptotic cells $(89 \pm 17 \%)$ showed a strong expression of TACE/ADAM17 (Fig. 3D). No staining was observed in control samples where the primary antibody was absent (Fig. $3 \mathrm{~A}^{\prime \prime}$ and $\mathrm{B}^{\prime \prime}$ ).

Immunoblotting using an anti-TACE/ADAM17 showed an intense band of FAS $(+)$ cells, which was significantly higher than in FAS $(-)$ cells (Fig. 4A and C). On the contrary, ADAM10 western blotting resulted in a band that was strong in FAS (-) and was not detected in FAS $(+)$ cells (Fig. 4A and C). The mRNA levels of the two studied proteins were similar in FAS $(+)$ and FAS (-) cells (Fig. 4B and D). The immunoblots and immunohistochemistry suggest that germ cell apoptosis is associated with an upregulation of TACE/ADAM17 and the absence of KIT extracellular domain.

Next, we investigated whether pharmacological inhibition of ADAM17 or ADAM10 could prevent the increase in apoptotic germ cells observed in 25-day-old rats. Intratesticular injection of different inhibitors, such as caspase or calpain inhibitors, is a procedure that has been used successfully in pubertal rat testes to determine 

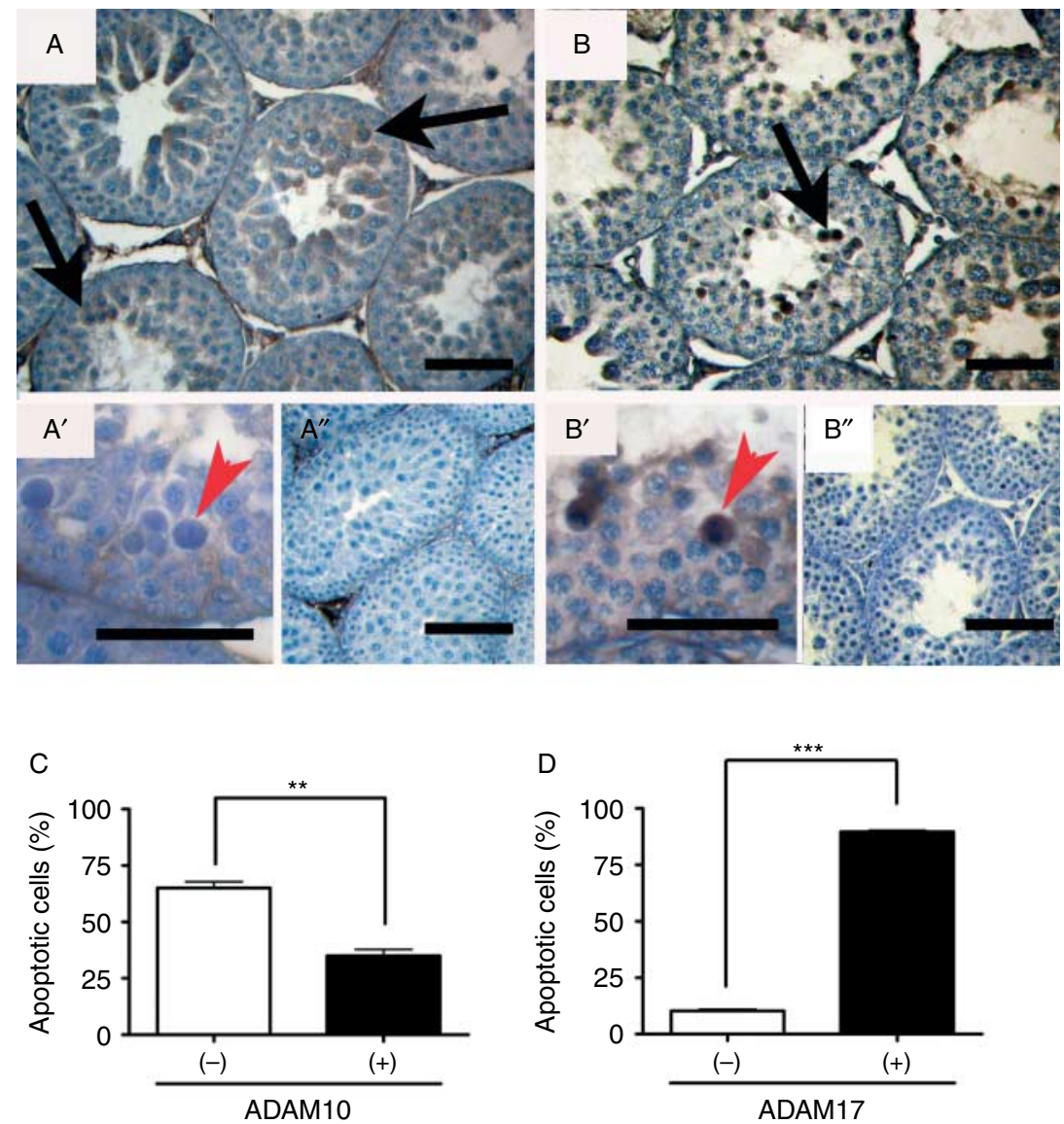

Figure 3 Localization of TACE/ADAM17 and ADAM10 in 25-day-old rat testes. (A) ADAM10 shows a cytoplasmic localization in pachytene spermatocytes in some seminiferous tubules (arrow). ( $\mathrm{A}^{\prime}$ ) Apoptotic (pycnotic) cells did not show labeling of ADAM10 (red arrowhead). (B) TACE/ADAM17 shows a rather homogeneous localization in all cells within the seminiferous tubules, specially in pycnotic cells (arrow). $\left(B^{\prime}\right)$ Apoptotic (pycnotic) cells show a strong label (red arrowhead). ( $A^{\prime \prime}$ and $B^{\prime \prime}$ ) Negative controls were the primary antibody was absent in the reaction. Apoptotic (pycnotic) germ cells were quantified in 25-day-old rats, and were classified by the presence $(+)$ or absence $(-)$ of ADAM10 (C) or ADAM17 (D). ${ }^{* *} P<0.01,{ }^{* * *} P<0.001$. Bars $50 \mu \mathrm{m}$. $\left(\mathrm{A}^{\prime}\right.$ and $\left.\mathrm{B}^{\prime}\right)$ Bars $25 \mu \mathrm{m}$. the role of specific enzymes in germ cell apoptosis (Castanares et al. 2005, Zheng et al. 2006, Codelia et al. 2008). All these reports have shown successful drug delivery inside seminiferous tubules. Two different inhibitors for ADAMs had been described before this work, GI254023X and GW280264X, which specifically block the activity of ADAM10 and TACE/ADAM17 respectively (Ludwig et al. 2005, Schulte et al. 2007). We injected these inhibitors independently in the testes of 24-day-old rats and evaluated apoptosis $24 \mathrm{~h}$ after, when rats were 25 days old. Intratesticular injection of $1 \mu \mathrm{M}$ ADAM10 inhibitor (GI254023X) did not modify the number of apoptotic cells, as compared with the control testes (Fig. 5B). However, intratesticular injection of 50 or $100 \mu \mathrm{M}$ of this inhibitor (196 or 392 ng/testis respectively) induced a significant increase in the number of apoptotic germ cells as compared with controls (Fig. 5A and $\mathrm{B}, * P<0.05$ ). TACE/ADAM17 (GW280264X) inhibitor at $1-\mu \mathrm{M}$ concentration (5.76 ng/testis) reduced the number of germ cells in apoptosis, but this result was not statistically significant (Fig. 5C). Higher concentrations, i.e. 50 or $100 \mu \mathrm{M}(288$ or 596 ng/testis respectively) of the ADAM17 inhibitor, did significantly reduce the number of apoptotic germ cells (Fig. 5A and C). Similar results were observed with TAPI-0 (data not shown).
Our results show that TACE/ADAM17 is expressed in germ cells undergoing apoptosis, and that its pharmacological inhibitor prevented physiological apoptosis during the first wave of spermatogenesis. On the other hand, ADAM10 seems to be related with survival or processes different from apoptosis in spermatogenesis.

\section{Induction of TACE/ADAM17 induces germ cell apoptosis}

To determine whether induction of TACE/ADAM17 by PMA induces germ cell apoptosis in vivo, 21-day-old rat testis were used because of the low rate of apoptosis, allowing the simple quantification of any increase in apoptosis. PMA-induced germ cell apoptosis in a concentration-dependent manner starting at $1 \mu \mathrm{M}$ (Fig. 6A and B). Germ cell apoptosis increased at $12 \mathrm{~h}$, and then peaked at $24 \mathrm{~h}$ after $5-\mu \mathrm{M}$ PMA treatment (Fig. 6C). Histological examination of treated testis showed that apoptotic cells were identified as spermatocytes, according to their position in the seminiferous epithelium (Fig. 7A). Intratesticular injection of $5-\mu \mathrm{M}$ PMA induced a significant increase in the number of pycnotic cells (Fig. 7A and B). In addition, 5- $\mu$ M PMA increased the number of apoptotic germ cells almost four times as evaluated by flow cytometry (Fig. 7C). In total, 
A

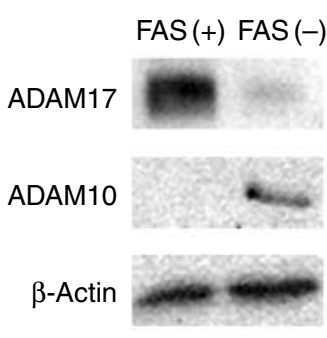

C

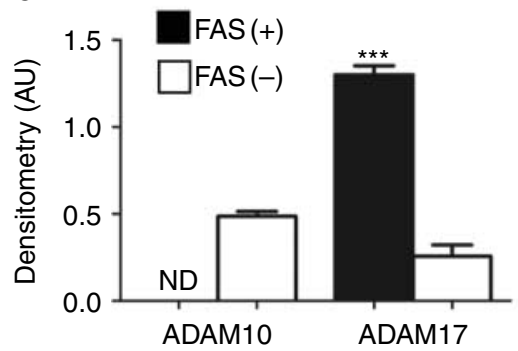

B FAS (+) FAS (-) T

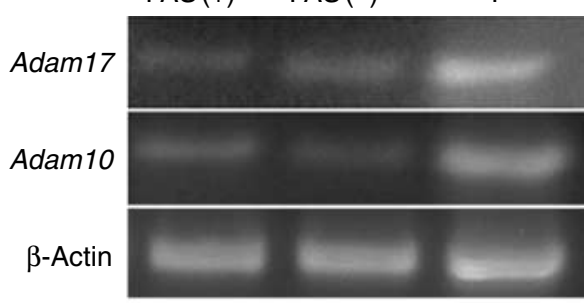

D

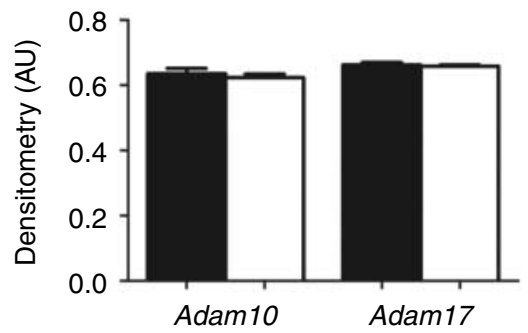

Figure 4 ADAMs detection in apoptotic germ cells. Apoptotic germ cells containing high levels of FAS (FAS (+)) were immunoisolated from 25-day-old rats. (A) ADAM17 protein levels were higher in FAS $(+)$ in comparison with FAS $(-)$. The opposite is observed with ADAM10. $\beta$-Actin was used as a loading control. (B) FAS (+) and FAS ( - ) cells show similar levels of mRNA of Adam17 and Adam10. Tis total testis. $\beta$-Actin was used as a loading control. (C and D) Quantification of ADAM10 and ADAM17 protein and mRNA levels respectively in FAS $(+)$ (black bars) and FAS (-) (white bars) fractions. Graphs show the intensity of each band relative to $\beta$-actin as a loading control. $n=3,{ }^{* * *} P<0.001$. ND, not detected.
500-nM TAPI-0, a well-known TACE/ADAM17 inhibitor, was able to prevent the increase in the apoptotic index and the number of germ cells in apoptosis as evaluated by flow cytometry (Fig. 7A-C). To establish whether PMA induces the upregulation of TACE/ADAM17 and KIT extracellular shedding from apoptotic germ cells, as is observed under physiological conditions, we performed immunohistochemistry against the different proteins, and then quantified the results as described in Materials and Methods. Results showed that $82 \pm 2.3 \%$ of apoptotic cells lacked the extracellular domain of KIT (Fig. 8A). On the contrary, $80 \pm 1.8 \%$ of apoptotic cells showed the intracellular domain, but only $6 \pm 3.1 \%$ of apoptotic cells stained positively for phosphorylated (active) KIT (Fig. 8A). Most of the apoptotic cells $(89 \pm 1.5 \%)$ lacked ADAM10, but $83 \pm 1.8 \%$ showed the expression of TACE/ADAM17 (Fig. 8B). Even more, we found that $5-\mu \mathrm{M}$ PMA induced an increase in the levels of TACE/ADAM17 at the cell surface as evaluated by flow cytometry (Fig. 8B).

Finally, we studied whether PMA effectively induces the processing of the extracellular domain of KIT. To this end, we isolated pachytene spermatocytes, and cultured them with or without $5 \mu \mathrm{M}$ PMA. Results showed that after $2 \mathrm{~h}$ of incubation, a band of around $60 \mathrm{kDa}$ of KIT (cleaved form) was observed only in
A
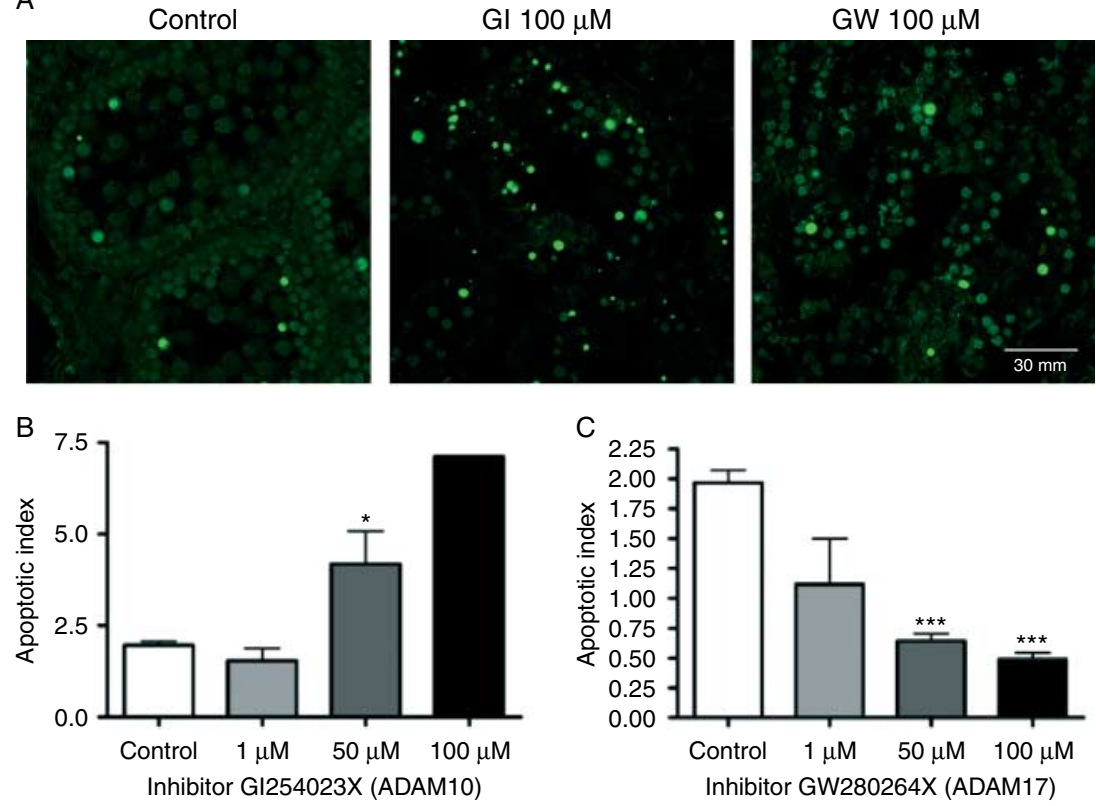

Reproduction (2010) 140 305-317

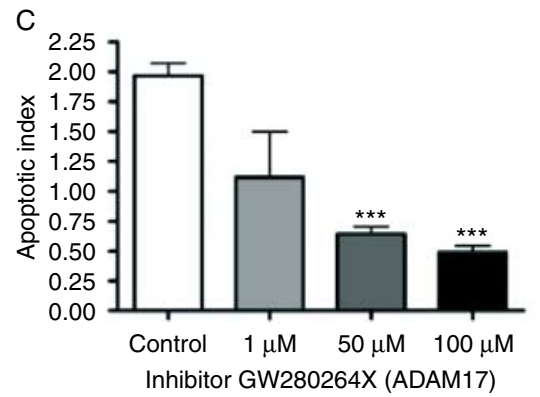

Figure 5 Effect of TACE/ADAM17 and ADAM10 inhibition on germ cell apoptosis. (A) 25-day-old rat testes (control) showed several apoptotic germ cells (green TUNEL staining). Injection of ADAM10 inhibitor (GI254023X) promoted an increase in the number of apoptotic germ cells. On the contrary, testes injected with ADAM17 inhibitor (GW280264X) showed fewer apoptotic germ cells. (B and C) The effect of ADAM10 and ADAM17 inhibition on germ cell apoptosis was concentration dependent $\left({ }^{*} P<0.05 ;{ }^{* * *} P<0.001, n=3\right)$. 
A

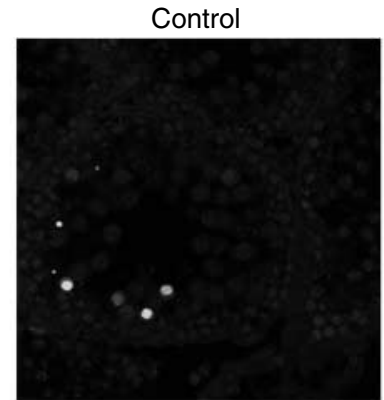

B

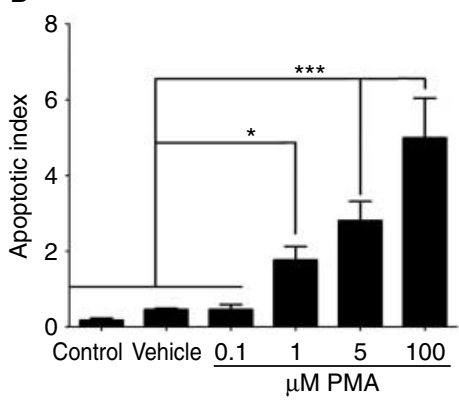

PMA $10 \mu \mathrm{M}$

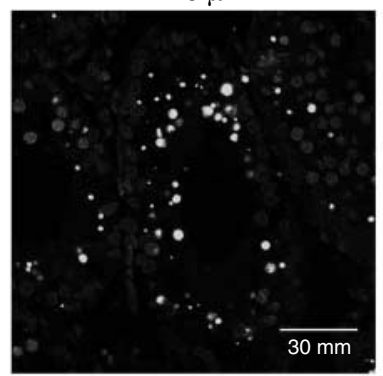

C

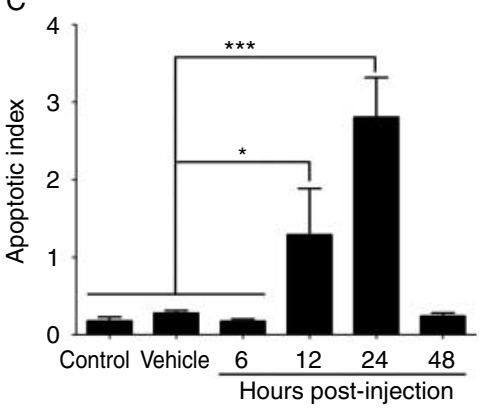

Figure 6 Phorbol ester (PMA) induces an increase in TUNEL-positive cells. (A) TUNEL-positive cells (fluorescent) of control testes or testes after $24 \mathrm{~h}$ of treatment that consisted of a 5- $\mu \mathrm{M}$ PMA injection. Bar $100 \mu \mathrm{m}$. (B) The apoptotic index (TUNELpositive cells/seminiferous tubule) was evaluated $24 \mathrm{~h}$ after treatment and increased in a concentration-dependent manner, starting at $1-\mu \mathrm{M}$ PMA. (C) Intratesticular injection of 5- $\mu \mathrm{M}$ PMA induced a significant increase in the apoptotic index after $12 \mathrm{~h}$, and then peaked at $24 \mathrm{~h}$ after treatment $(n=3, * P<0.05, * * * P<0.001)$. those spermatocytes cultured in the presence of PMA (Fig. 9A). Additionally, a similar result was observed when a testis fragment was used instead of isolated spermatocytes (Fig. 9B).

\section{Discussion}

In this work, we have provided evidence indicating that TACE/ADAM17 plays a role in inducing germ cell apoptosis through its participation in the extracellular domain shedding of KIT. This is the first report that shows the involvement of TACE/ADAM17 in apoptosis in vivo, and that provides a new molecular mechanism to regulate mammalian spermatogenesis. Despite the fact that KIT is involved in germ cell survival, its role during normal germ cell apoptosis has not been previously determined. Our results were obtained using a new model of germ cell apoptosis, which allows its study under normal and pathological conditions.

We used four different experimental approaches (immunohistochemistry, immunofluorescence, western blotting, and flow cytometry) to show that apoptotic germ cells lack the extracellular domain of KIT. Interestingly, apoptotic germ cells have the intracellular domain of KIT unphosphorylated (inactive), which strongly suggests that ectodomain shedding inhibits and/or prevents the activation of the intracellular survival pathway elicited by KIT. We do not know whether shedding of the KIT extracellular domain occurs before or during ligand binding, but we hypothesize that the intracellular survival signaling pathway induced by this receptor is shut down in apoptotic cells. Previously, it has been shown in cell lines that pharmacological inhibition of survival pathways leads to apoptosis induction (Levy et al. 2009). Therefore, we proposed that KIT extracellular shedding is a signal that leads to apoptosis induction under physiological conditions.

A previous report have shown that the extracellular domain of KIT is shed by TACE/ADAM17 in human embryonic kidney cells (Cruz et al. 2004), but a similar action has not been documented for ADAM10 or any other extracellular protease (Huovila et al. 2005). Our results link KIT extracellular domain shedding to apoptosis under in vivo conditions. Interestingly, TACE/ADAM17 was homogeneously distributed in testes from 25-day-old rats, but was significantly increased in apoptotic cells, as evaluated by immunohistochemistry and western blot. During this study, we performed immunofluorescence studies in order to colocalize ADAM proteins and with apoptotic cells, as determined by the TUNEL assay, but in our hands the available antibodies against ADAM17 or ADAM10 did not give a signal strong enough to allow their detection. Even though the identification of apoptotic cells by bright field microscopy is not a widely used procedure, our own studies have shown that pycnotic germ cells in pubertal rat testis are easily identified, and they show several bona fide apoptosis markers (Moreno et al. 2006a, Ortiz et al. 2009). Our results are suggestive that mRNA levels of TACE/Adam17 are similar in apoptotic and nonapoptotic cells, but they need to be further confirmed by quantitative PCR. In order to differentiate the differential contribution of TACE/ADAM17 and ADAM10, we used two different inhibitors for ADAMs, GI254023X and GW280264X, which specifically block the activity of ADAM10 and TACE/ADAM17 respectively 

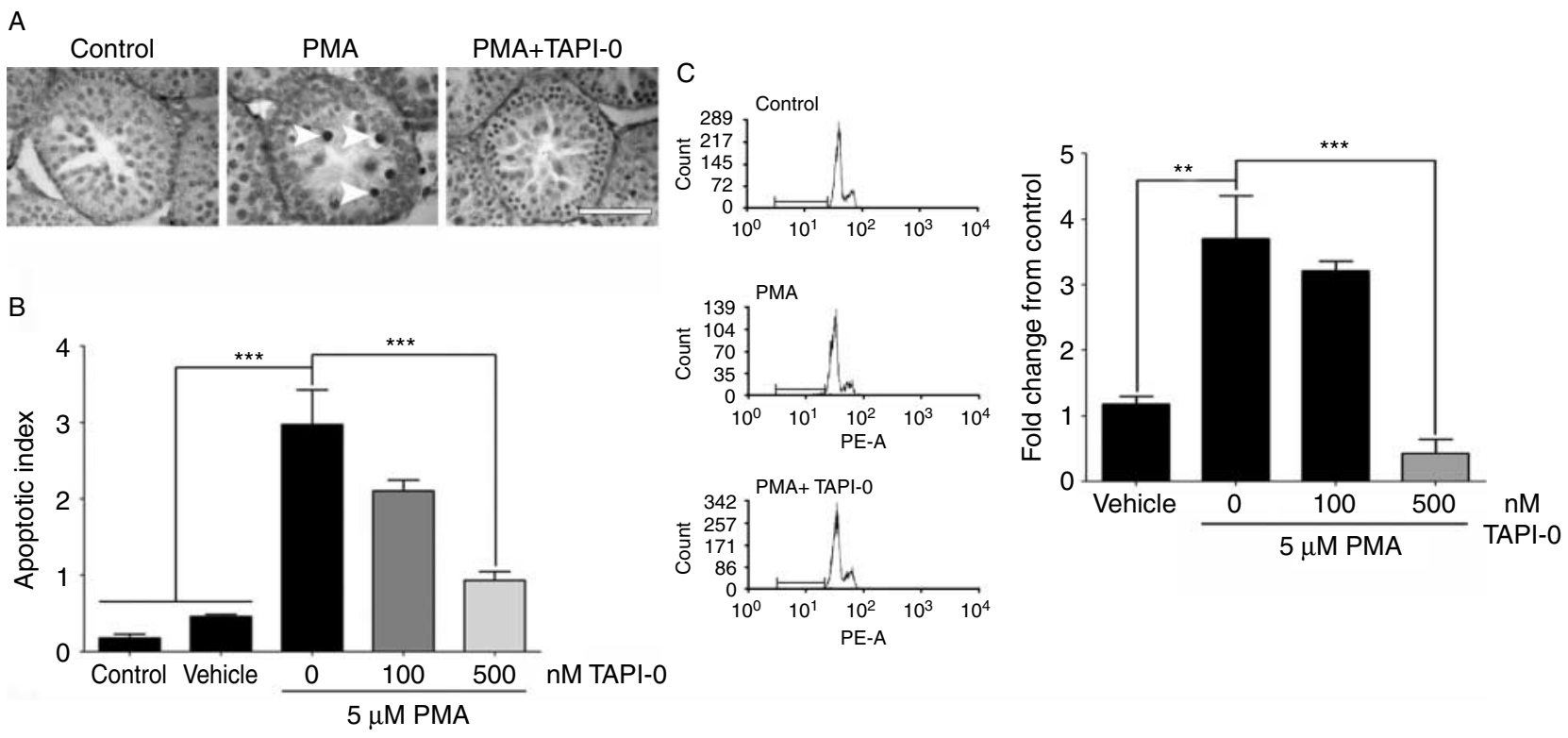

Figure 7 TAPI-0 prevents PMA-induced germ cell apoptosis. (A) Histological sections of 21-day-old rats (Control), 24 h after 5 - $\mu$ M PMA alone (PMA) or with 500 nM TAPI-0 (PMA+TAPI-0). PMA-treated testes showed several pycnotic (apoptotic) cells (arrowheads), which were rarely observed in control or when TAPI-0 was included in the treatment. (B) The apoptotic index increased significantly after $24 \mathrm{~h}$ of $5-\mu \mathrm{M}$ PMA treatment, but was prevented in the presence of an increasing concentration of TAPI-0. (C) Flow cytometry analysis of 21-day-old rat testes: control, treated with $5 \mu \mathrm{M}$ PMA alone or with $500 \mathrm{nM}$ TAPI-0. The left hand graph shows the histograms distributed according to cell cycle stage $\left(\mathrm{G}_{1} / \mathrm{G}_{0}, \mathrm{~S}\right.$ and $\left.\mathrm{G}_{2} / \mathrm{M}\right)$, and the horizontal bar indicates the sub- $\mathrm{G}_{0} / \mathrm{G}_{1}$ population, which are apoptotic cells. The graph shows the fold change of cells in sub- $\mathrm{G}_{0}$ after different treatments relative to control (treated with vehicle alone). $n=3,{ }^{* *} P<0.01,{ }^{* * *} P<0.001$.

(Ludwig et al. 2005, Schulte et al. 2007). Purified TACE/ ADAM17 shows a IC 50 of $8 \mathrm{nM}$ for GW280264X, as compared with TAPI-0, a classical TACE/ADAM17 inhibitor, which has an $\mathrm{IC}_{50}$ of $100 \mathrm{nM}$ (Mullberg et al. 1995, Hundhausen et al. 2003, Ludwig et al. 2005). However, previous studies have used $3-\mu \mathrm{M}$ GW280264X to specifically inhibit TACE/ADAM17 extracellular shedding receptor/ligands in cell cultures (Abel et al. 2004, Arduise et al. 2008). In this study, we observed a significant inhibition of germ cell apoptosis with a $10-\mu \mathrm{l}$ intratesticular injection of a solution containing $50 \mu \mathrm{M}$ GW280264X. Previous studies have indicated that 25-day-old rat testes have a volume around $150 \mu \mathrm{l}$ (Zhengwei et al. 1990), thus assuming homogeneous distribution, the final concentration of the inhibitor is $300 \mathrm{nM}$, which is even less than those used in cultured cells. Even more, an important reduction of germ cell apoptosis was observed using an injection of a solution containing $1 \mu \mathrm{M}$ of inhibitor $(6.6 \mathrm{nM}$ final intratesticular), which is lower than the $\mathrm{IC}_{50}$ reported using the purified enzyme, that explains the important, but non statiscally significant reduction observed under this condition. Interestingly, induction of TACE/ADAM17 by PMA promotes the processing of KIT and germ cell apoptosis. PMA has been widely used as an inductor of shedding activity in different cell lines. The mechanisms underlying TACE/ADAM17 activity could involve in the activation of p38 MAPK, ERK1/2 and PKC (Blass et al. 2002, Tang et al. 2002). In fact, TACE/ADAM17 has been shown to be phosphorylated by ERK at threonine 735, which is associated with PKC-regulated NTRK1(TrkA) cleavage (Diaz-Rodriguez et al. 2002). Interestingly, the percentage of apoptotic cells expressing TACE/ADAM17 under physiological conditions and after PMA treatment was almost identical, suggesting similar signaling in both situations. Our results indicate that PMA-induced germ cell apoptosis was mediated by TACE/ADAM17 since TAPI-0 was able to prevent this effect at concentrations close to the $\mathrm{IC}_{50}$ reported in other systems, suggesting that this inhibitor was effectively blocking TACE/ADAM17 activity. In addition, pharmacological inhibition of TACE/ADAM17 prevented physiological germ cell apoptosis in 25-day-old rats, which strengthens the idea that physiological and PMA-induced apoptosis are driven by TACE/ADAM17 activation. These findings agree with previous data indicating that compared with wild-type mast cells, cells harboring a catalytically inactive TACE/ADAM17 had a decreased constitutive shedding and an increased basal surface expression of KIT, with diminished apoptosis in response to KIT ligand deprivation (Cruz et al. 2004). Our data support the hypothesis that TACE/ADAM17 activity is required during germ cell apoptosis. Mice harboring an inactive form of TACE/ADAM17 die early in development, prohibiting the study of spermatogenesis (Blobel 2005, Huovila et al. 2005). However, it has been recently shown that male mice harboring a tissue-specific conditional inactivation of TACE/ADAM 17 driven by a SOX9 promoter show a subfertile phenotype during adulthood (Horiuchi et al. 2009). These results suggest 


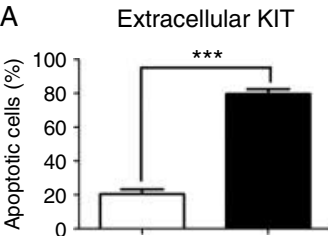

$(+)$

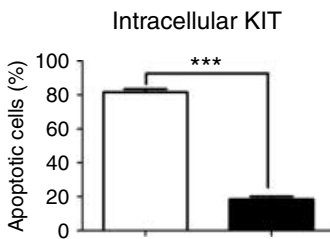

$(+)$

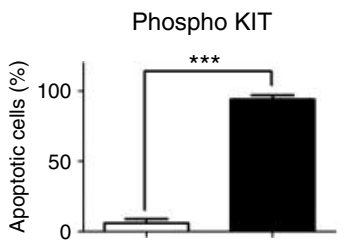

$(+)$

$(-)$

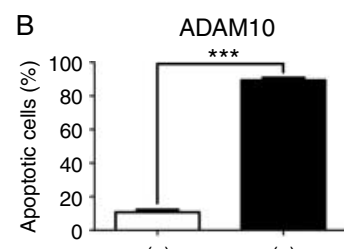

$(+)$

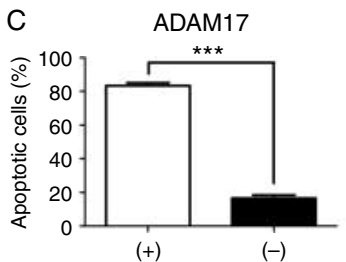

D

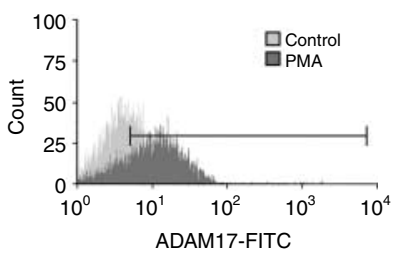

Figure 8 KIT shedding and TACE/ADAM17 in apoptotic cells after phorbol ester (PMA) treatment. Testes of 21-day-old rats were intratesticularly injected with 5- $\mu \mathrm{M}$ PMA, $24 \mathrm{~h}$ later they were fixed and the presence of the extracellular and intracellular domain of KIT, as well as its active (phosphorylated) form, were assessed by immunohistochemistry. Likewise, (B) ADAM10 and (C) TACE/ADAM17 were detected in apoptotic cells. A total of 300 apoptotic (pycnotic) cells were quantified (100 per rat) in randomly chosen tubules. The graphs show the percentage of apoptotic cells with $(+)$ or without $(-)$ label in each case. $n=3, * * * P 0.001$. (D) Flow cytometry detection of ADAM17 in live seminiferous tubule cells after treatment with 5- $\mu \mathrm{M}$ PMA for 2 h. Light grey area represents control cells (autofluorescence), and dark grey shows the cells with the ADAM17 antibody. Horizontal bar indicates positive fluorescence area.

that TACE/ADAM17 could have an important role in mammalian spermatogenesis and male fertility. In addition, our results support the hypothesis that upregulation of TACE/ADAM17 is an important step in triggering germ cell apoptosis.

ADAM10 was mainly detected in nonapoptotic ((FAS $(-)$ ) cells and only barely in apoptotic (FAS $(+))$ cells. In accordance with this data, immunohistochemistry showed that this enzyme was mostly localized in the cytoplasm of pachytene spermatocytes, and only around $30 \%$ of apoptotic (pycnotic) cells showed a marked expression of this enzyme (Fig. 3A and B). Curiously, pharmacological inhibition of ADAM10 induced a significant increase in the number of apoptotic cells, which is contrary to the effect observed with the TACE/ADAM17 inhibitor. This result suggests that the inhibition of ADAM10 elicits apoptotic signals in the rat testis. Recently, it has been shown that ADAM10 regulates surface expression of FAS ligand (FASL) by inducing the shedding of its extracellular domain (Schulte et al. 2007). We have shown that activation of the FAS receptor and the extrinsic pathway of apoptosis are relevant in naturally occurring apoptosis in 25-dayold rat testes (Lizama et al. 2007). It therefore seems possible that ADAM10 inhibition increases the half-life of FASL at the Sertoli cell surface, resulting in a juxtacrine signal that elicits apoptosis in germ cells. On the other hand, ADAM10 has been shown to be the sheddase of several growth factors involved in germ cells survival, such as TNF, EGF, or NOTCH, all of them present in the testis (Hayashi et al. 2001, von Schonfeldt et al. 2004, Mezyk-Kopec et al. 2009, Yao et al. 2009). Alternatively, the inhibition of ADAM10 activity may prevent other autocrine/paracrine regulation processes leading to germ cell apoptosis. Further studies are necessary to fully understand the role of ADAM10 in spermatogenesis.

We have previously shown that germ cell apoptosis during the first wave of spermatogenesis is associated with an upregulation of FAS, a death receptor involved in the extrinsic pathway of apoptosis (Lizama et al. 2007). We have shown that they express several apoptosis marker which strongly suggest that they are indeed in the process (Lizama et al. 2007, Vergara et al. 2010). Whether or not all apoptotic spermatogenic cells are FAS positive remains controversial, and it is possible that more than one cell death pathway could take place in germ cells. In fact, the role of the FAS-FASL system in male germ cell apoptosis has been controversial, since inactivating mutations of these proteins do not seem to have an effect on spermatogenesis. Our own studies have shown that the upregulation of FAS and caspase-8 activation is an important step to trigger germ cell apoptosis in pubertal rat testis. In this context, it is possible that under the condition where the FAS-FASL system is inactive, other signaling pathways take over

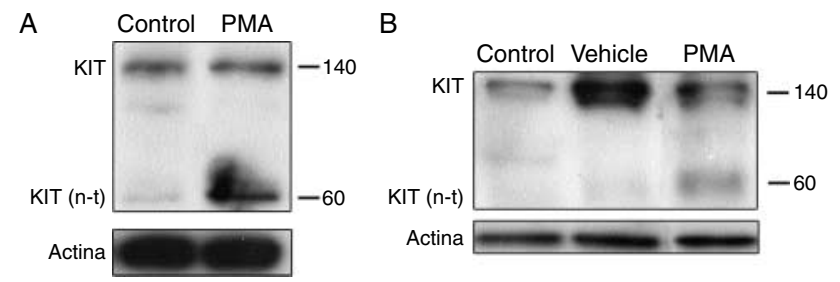

Figure 9 Phorbol ester (PMA) induces KIT processing in germ cells. Isolated spermatocytes (A) or testes fragments (B) were cultured for $2 \mathrm{~h}$ in KHB-lactate medium alone or in the presence of 5- $\mu \mathrm{M}$ PMA or vehicle $(0.001 \%$ DMSO). Full-length KIT or its processed form (n-t) was detected by western blot using an antibody against the $\mathrm{N}$-terminal domain. 
this process. Germ cells can elicit both the extrinsic and intrinsic pathway (Moreno et al. 2006a, Lizama et al. 2007, Codelia et al. 2008), but it remains to be determined if germ cell apoptosis under physiological and pathological conditions use similar or different mechanisms. Even though no phenotype is observed in mice harboring inactivating mutations in FAS and FASL, the literature shows a genetic link between germ cell apoptosis induced by KIT inactivation and the extrinsic pathway of apoptosis induced by FAS (Sakata et al. 2003). It has also been shown that blocking FASL in vitro prevents germ cell apoptosis and seems important for germ cell apoptosis in Sertoli cell-only patients (Pentikainen et al. 1999, Kim et al. 2007). We propose that TACE/ADAM17 activation leads to the shedding of the KIT extracellular domain, thereby inhibiting survival signals, which in turn will induce apoptosis and FAS upregulation. Thus, our results show that shedding of extracellular KIT domain by ADAM17 is one of the elements triggering physiological germ cell apoptosis during the first round of spermatogenesis. It remains to be discovered whether the activation of TACE/ADAM17 is involved during germ cell apoptosis in adult rats or after insults such as temperature, hormone deprivation, or DNA-damaging agents.

\section{Materials and Methods}

\section{Animals}

In order to induce apoptosis in germ cell, we choose male Sprague-Dawley rats of 21 days old because they have almost undetectable levels of apoptosis. To study the physiological apoptosis, we used male Sprague-Dawley rats that were 25 days old because it has been shown that they have a high rate of apoptosis at this age. ADAM protease inhibitors were used in 24-day-old rats, in this way we allowed them to work for $24 \mathrm{~h}$, and their effect was assayed in 25-day-old rats. Animals were acquired from the Animal Facility of our Faculty. The rats were housed under a $12 \mathrm{~h}$ light: $12 \mathrm{~h}$ darkness cycle, and provided with water and rat chow ad libitum. The rats were killed by cervical dislocation after exposure to $\mathrm{CO}_{2}$ for $30 \mathrm{~s}$. Investigations were conducted in accordance with the Guide for the Care and Use of Agricultural Animals in Agricultural Research and Teaching, published by the Consortium for Developing a Guide for the Care and Use of Agricultural Animals in Agricultural Research and Teaching, First Edition, 1988. All animal protocols were endorsed by the Chilean National Fund of Science and Technology (FONDECYT).

\section{Chemicals and antibodies}

Rabbit polyclonal antibodies against intracellular KIT and TACE/ADAM17 were purchased from Santa Cruz Biotechnology (Santa Cruz, CA, USA). The rat polyclonal antibody against 719) was purchased from Cell Signaling (Danvers, MA, USA). The monoclonal mouse antibody against actin was purchased from Sigma, and the mouse MAB against
ADAM10 was purchased from Santa Cruz Biotechnology. Anti- $\beta$-KIT extracellular domain (ACK2) was purchased from Millipore (Billerica, MA, USA). The rabbit polyclonal antibody against phospho rabbit and anti-KIT (Tyr-mouse UltraVision Detection Systems were obtained from LabVision (Fremont, CA, USA). Anti-Golgin160 was prepared as previously described (Moreno et al. 2006b). PMA and TAPI-0 were purchased from Merck. The GI254023X and GW280264X inhibitors were synthesized as described before (Ludwig et al. 2005, Schulte et al. 2007). PMA, TAPI-O, GI254023X, or GW280264X were first dissolved in DMSO and stored a $4{ }^{\circ} \mathrm{C}$. Working solutions were made by diluting the stock solution in the proper volume of PBS (see below).

\section{Spermatocyte separation with a discontinuous density gradient}

Prepubertal male rats of 24-day-old were killed by cervical dislocation, and both testes were extracted, decapsulated, and digested with $0.5 \mathrm{mg} / \mathrm{ml}$ collagenase I (Sigma) and $0.4 \mu \mathrm{g} / \mathrm{ml}$ DNase (Sigma) for $15 \mathrm{~min}$ at $30^{\circ} \mathrm{C}$ in a modified KrebsHenseleit buffer (KHB) medium containing $0.141 \mathrm{~g} / \mathrm{l}$ magnesium sulfate (Anhydrous), $0.16 \mathrm{NaH}_{2} \mathrm{PO}_{4}, 0.35 \mathrm{~g} / \mathrm{KCl}$, and $6.9 \mathrm{~g} / \mathrm{l} \mathrm{NaCl}$ supplemented with $5 \mathrm{mM}$ L-lactate (Sigma) (KHBlactate) and $0.5 \mathrm{mg} / \mathrm{ml}$ collagenase I. Seminiferous tubules were washed three times in KHB-lactate medium, and cells were mechanically disintegrated by continuous pipetting in $\mathrm{KHB}$ solution containing $0.4 \mu \mathrm{g} / \mathrm{ml}$ DNase. The cell suspension was filtered through a nylon membrane of 250 and $70 \mu \mathrm{m}$ (Small Parts) and subsequently washed once in KHB-lactate medium. Spermatocytes were resuspended in $1.5 \mathrm{ml}$ of KHBlactate containing $0.2 \mu \mathrm{g} / \mathrm{ml}$ DNase and $0.7 \%$ of BSA. Then, spermatocytes were purified through a Percoll gradient (Van Pelt et al. 1996). Briefly, an iso-osmotic Percoll suspension was prepared containing $90 \%$ Percoll in KHB-lactate. A discontinuous density gradient was made by diluting the iso-osmotic Percoll suspension with KHB-lactate containing $0.2 \mu \mathrm{g} / \mathrm{ml}$ DNAase and $0.7 \%$ of BSA. The percentages of Percoll were from top to bottom - 10, 20, 25, 30, and 40\%. The cell suspension was layered on top of the gradient in $500 \mu \mathrm{l}$ $\mathrm{KHB}$-lactate containing $0.2 \mu \mathrm{g} / \mathrm{ml}$ DNase and $0.7 \%$ of BSA. The gradient was centrifuged at $800 \mathrm{~g}$ for $30 \mathrm{~min}$ at $18{ }^{\circ} \mathrm{C}$. Cells collected at the interphase $25-30 \%$ were identified as spermatocytes with a $75 \%$ of purity. Contaminant cells were mostly Sertoli and fibrolast-like cells (probably myoid cells).

\section{Tissue culture}

Isolated testes from 21-day-old rats were decapsulated and cut into three sections of equal size, and then cultured in $\mathrm{KHB}-$ lactate medium. Then, they were cultured for $2 \mathrm{~h}$ in the presence of medium alone, $0.01 \%$ DMSO (Vehicle) or $5 \mu \mathrm{M}$ PMA.

\section{Intratesticular injections}

Pubertal rats of 24-day-old were anesthetized with ketamine: xylacine ( 1 and $75 \mathrm{mg} / \mathrm{kg}$ ) i.m. The testes were exteriorized through a low midline incision. Ten microliters of a TAPI-0 solution, 1-100 $\mu \mathrm{M}$ ADAM inhibitors or 0.1-100 $\mu \mathrm{M}$ PMA 
dissolved in PBS were injected in the testes via a 30-G needle. Following drug delivery, the testes were returned to the peritoneal cavity, and the incision was closed. In each experiment, one testis was used for histology and the other was used for biochemical assays. As a control, PBS was injected into the testes. Three different rats were used for all experiments, and they were killed $24 \mathrm{~h}$ after injection.

\section{Histology}

Testes were fixed in Bouin's solution and embedded in paraffin. Sections were counterstained with periodic acid-Schiff and hematoxylin in order to visualize pycnotic cells. We have previously shown that pycnotic germ cells express apoptotic markers such as active caspase-3 and stain positively for TUNEL (Moreno et al. 2006a).

\section{Immunohistochemistry}

ADAM proteins were localized in paraffin embedded crosssections of rat testis fixed in $4 \%$ paraformaldehyde (PFA). The samples were first treated with $3 \% \mathrm{H}_{2} \mathrm{O}_{2}$ in PBS, for $5 \mathrm{~min}$, then, to prevent unspecific binding, a solution containing $4 \%$ BSA in PBS was applied for 5 min. Primary antibody against the KIT extracellular domain $(2.5 \mu \mathrm{g} / \mathrm{ml})$, the KIT intracellular domain $(2 \mu \mathrm{g} / \mathrm{ml})$, TACE/ADAM17 $(2 \mu \mathrm{g} / \mathrm{ml})$, or ADAM10 $(2 \mu \mathrm{g} / \mathrm{ml})$ were dissolved in $4 \%$ BSA-PBS, and the solution was applied and incubated overnight at $4{ }^{\circ} \mathrm{C}$ in a humidified chamber after being washed twice for $5 \mathrm{~min}$ in a Tris- $\mathrm{HCl}$ buffer, pH 7.6, with $0.3 \mathrm{M} \mathrm{NaCl}$ and $0.1 \%$ Tween 20 . Biotinylated secondary antibody, streptavidin-biotinylated peroxidase complex, amplification reagent (biotinyl tyramide), and peroxidase-conjugated streptavidin were applied step-by-step for 15 min each. Afterwards, incubation slides were washed twice in a buffer for 3 min each. Finally, a substrate-chromogen solution consisting of concentrated Tris- $\mathrm{HCl}$ and $0.8 \% \mathrm{H}_{2} \mathrm{O}_{2}$ (substrate) and 3,3-diaminobenzidine tetrahydrochloride (DAB) solutions (chromogen) were applied for $5 \mathrm{~min}$ and washed in distilled water. Samples were observed under a phase contrast microscope (Optiphot-2; Nikon, Tokyo, Japan) and photographed with a digital camera (CoolPix 4500, Nikon).

\section{TUNEL analysis}

Apoptotic fragmentation of DNA in histological sections of rat testes was evaluated by TUNEL analysis (Dead End System; Promega). Standard protocols for paraffin sections were followed (Moreno et al. 2006a).

Samples were observed under phase contrast and fluorescence microscopy (Optiphot-2, Nikon) by filters for wavelengths at 460-500 nm (excitation) and 510-560 nm (barrier). Micrographs were taken with a digital camera (CoolPix 4500, Nikon). TUNEL-positive germ cells were quantified in each tissue section by counting the number of TUNEL-positive cells in each round seminiferous tubule. The apoptotic index was calculated as the average number of TUNEL-positive cells per seminiferous tubule. Three testicular histological sections were taken per rat, with a minimum of 100 randomly selected tubules in each tissue section. The data are presented as the mean ( \pm s.D.) from three rats for each specified age. The apoptotic index was calculated as the average number of TUNEL-positive cells per seminiferous tubule cross-section as described before (Moreno et al. 2006a, Codelia et al. 2008). Three testicular histological sections were taken per rat (three rats total), and a minimum of 100 randomly selected tubules were counted in each tissue section (a total of 900 tubules were recorded per treatment). The data represent the mean \pm s.D.

\section{Immunofluorescence}

Rat testes were fixed in 4\% PFA and embedded in paraffin. Sections $(5-7-\mu \mathrm{m}$ thick) were cut and rehydrated. Nonspecific binding sites were blocked by incubating the sections in $2 \%$ BSA-PBS for $1 \mathrm{~h}$. Tissue sections were then incubated (overnight at $4{ }^{\circ} \mathrm{C}$ in a humidified chamber) with the antibody against the KIT extracellular domain $(2.5 \mu \mathrm{g} / \mathrm{ml})$. The next day, the slides were washed in PBS, incubated with Alexa 488 conjugated to goat anti-rabbit IgG (Molecular Probes, Eugene, OR, USA) for $1 \mathrm{~h}$ at room temperature, washed, and mounted with a fluorescence protector medium (VectaShield, Burlingame, CA, USA). In order to evaluate co-localization with TUNEL, samples were observed with laser scanning confocal microscopy (Pascal, Zeiss, Göttingen, Germany).

\section{Protein extraction and western blot}

FAS $(+)$ and FAS $(-)$ cells were isolated from 25-day-old rat testes as previously described (Lizama et al. 2007). Protein extraction was performed by homogenizing isolated seminiferous tubules in buffer $\mathrm{A}(1 \%$ Triton $\mathrm{X}-100, \mathrm{NaCl} 1 \mathrm{M}$, EDTA $1 \mathrm{mM}$, phenylmethylsulphonyl fluoride $10 \mathrm{mg} / \mathrm{ml}$, Tris- $\mathrm{HCl}$ $20 \mathrm{mM}, \mathrm{pH} 7.0$ ), and then centrifuged for $10 \mathrm{~min}$ at $9300 \mathrm{~g}$. The samples were run on a $12 \%$ SDS-PAGE under reducing and denaturing conditions, and then transferred to nitrocellulose at $30 \mathrm{~V}$ overnight or $100 \mathrm{~V}$ for $1.5 \mathrm{~h}$. The nitrocellulose

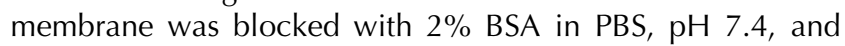
then incubated overnight at $4{ }^{\circ} \mathrm{C}$ with anti-ADAM1 $7(0.5 \mu \mathrm{g} / \mathrm{ml})$, anti-ADAM10 $(0.2 \mu \mathrm{g} / \mathrm{ml})$, or anti- $\beta$-actin $(0.9 \mu \mathrm{g} / \mathrm{ml})$ antibodies. After extensive washing with PBS plus $0.05 \%$ Tween 20 (PBS-Tween), the membrane was incubated with a secondary antibody conjugated to peroxidase (KPL, Gaithersburg, MD, USA) diluted 1:3000 in PBS-BSA for $1 \mathrm{~h}$ at room temperature. Protein bands were revealed using the Super Signal West Pico chemiluminescent substrate (Pierce, Rockford, IL, USA).

\section{Apoptosis and cell cycle analysis}

Seminiferous tubules were separated by continuous pipetting in $1.5 \mathrm{ml} \mathrm{KHB}$ (plus 1\% BSA) medium (2 g/l D-glucose, $0.141 \mathrm{~g} / \mathrm{l}$ magnesium sulfate (Anhydrous), $0.16 \mathrm{NaH}_{2} \mathrm{PO}_{4}, 0.35 \mathrm{~g} / \mathrm{l} \mathrm{KCl}$, and $6.9 \mathrm{~g} / \mathrm{l} \mathrm{NaCl}$ ) with $15 \mu \mathrm{l}$ of a collagenase solution $(0.5 \mathrm{mg} / \mathrm{ml})$ added. Tubuli were decanted while maintaining Leydig and blood cells suspended in the medium, which was consequently discarded. Collagenase causes the tubule walls to release germ and Sertoli cells. Using a syringe with a 21-G needle, the individual cells were further liberated. Finally, the 
solution was filtered through a $50-\mu \mathrm{m}$ filter. To analyze cell cycles, the cell suspension in KHB solution was pelleted, and then fixed in $70 \%$ ethanol overnight. As described by Riccardi \& Nicoletti (2006) on the day of analysis, the cells were pelleted and washed once with PBS. The pellet was then dissolved in a cell cycle buffer containing $0.1 \%$ sodium citrate, $0.3 \%$ Triton X-100 (both Sigma-Aldrich Co.), $50 \mu \mathrm{g} / \mathrm{ml}$ propidium iodide, and $50 \mu \mathrm{g} / \mathrm{ml}$ RNase A (both Invitrogen Corporation) dissolved in distilled water. The samples were then analyzed within 10 min of buffer addition in a Coulter Epics XL cytometer; 10000 gated events were acquired. All data were analyzed with software FCS express V2.0 (De Novo Software, Los Angeles, CA, USA).

\section{RT-PCR}

Total RNA of decapsulated testes was isolated using TRIzol Reagent (Invitrogen) according to the manufacturer's recommendations. Total RNA was quantified, and after confirmation of its integrity, cDNA was generated from $1 \mu \mathrm{g}$ of RNA using random primers and SuperScript II Reverse Transcriptase (Invitrogen). The cDNA obtained was amplified by a PCR of 30 cycles using Taq polymerase (Fermentas) in $50 \mu \mathrm{l}$ of the incubation mixture. Several primer sets were used to obtain the PCR products: Adam10 forward 5'-CCTACGAATGAAGAGGGAC- $3^{\prime}$ and reverse $5^{\prime}$-ATCACAGCTTCTCGTGTTCC- ${ }^{\prime}$ Adam 17 forward $5^{\prime}$-GTTGGTGAGCCTGACTCTA-3' and reverse 5'-CCTCTTGTGGAGACTTGA-3' Gapdh forward 5'-TCCACCACCCTGTTGCTGTA-3' and reverse 5'-ACCACAGTCCATGCCATCAC- $3^{\prime}$. Primers were designed to have a $\mathrm{TM}$ of $60{ }^{\circ} \mathrm{C}$. The mixture was incubated at $94^{\circ} \mathrm{C}$ for $2 \mathrm{~min}$ in order to denature the DNA, then 30 cycles of $60^{\circ} \mathrm{C}$ for $45 \mathrm{~s}$ followed by $72{ }^{\circ} \mathrm{C}$ for 1 min and $94{ }^{\circ} \mathrm{C} 45 \mathrm{~s}$. Program was finished with $5 \mathrm{~min}$ at $72{ }^{\circ} \mathrm{C}$. Aliquots of the PCR products were run in a $1 \%$ agarose gel and then stained with $0.1 \mu \mathrm{g} / \mathrm{ml}$ ethidium bromide. Bands obtained were analyzed by measuring the pixels with Adobe Photoshop 7.0 (Adobe System Incorporated), and normalized to Gapdh mRNA levels.

\section{Statistical analysis}

For mean comparisons, we used ANOVA. When the ANOVA test showed statistical differences, the Student-Newman-Keuls test was used to discriminate between groups. The $\chi^{2}$ test was used for comparison of frequencies. Statistical significance was defined as $P<0.05$ (Sokal 1995).

\section{Supplementary data}

This is linked to the online version of the paper at http://dx.doi. org/10.1530/REP-10-0104.

\section{Declaration of interest}

The authors declare that there is no conflict of interest that could be perceived as prejudicing the impartiality of the research reported.

\section{Funding}

This work was financed by a grant from the Chilean Research Council (FONDECYT, 1070360) to R D Moreno. A Ludwig is supported in part by IZKF Biomat. and SFB 542, project A12.

\section{References}

Abel S, Hundhausen C, Mentlein R, Schulte A, Berkhout TA, Broadway N, Hartmann D, Sedlacek R, Dietrich S, Muetze B et al. 2004 The transmembrane CXC-chemokine ligand 16 is induced by IFN-gamma and TNF-alpha and shed by the activity of the disintegrin-like metalloproteinase ADAM10. Journal of Immunology 172 6362-6372.

Arduise C, Abache T, Li L, Billard M, Chabanon A, Ludwig A, Mauduit P, Boucheix C, Rubinstein E \& Le Naour F 2008 Tetraspanins regulate ADAM10-mediated cleavage of TNF-alpha and epidermal growth factor. Journal of Immunology 181 7002-7013.

Bedell MA \& Mahakali Zama A 2004 Genetic analysis of kit ligand functions during mouse spermatogenesis. Journal of Andrology $\mathbf{2 5}$ 188-199.

Billig H, Furuta I, Rivier C, Tapanainen J, Parvinen M \& Hsueh AJ 1995 Apoptosis in testis germ cells: developmental changes in gonadotropin dependence and localization to selective tubule stages. Endocrinology 136 5-12.

Blass M, Kronfeld I, Kazimirsky G, Blumberg PM \& Brodie C 2002 Tyrosine phosphorylation of protein kinase Cdelta is essential for its apoptotic effect in response to etoposide. Molecular and Cellular Biology 22 182-195.

Blobel CP 2005 ADAMs: key components in EGFR signalling and development. Nature Reviews. Molecular Cell Biology 6 32-43.

Blume-Jensen P, Jiang G, Hyman R, Lee KF, O'Gorman S \& Hunter T 2000 $\mathrm{Kit} / \mathrm{stem}$ cell factor receptor-induced activation of phosphatidylinositol $3^{\prime}$-kinase is essential for male fertility. Nature Genetics 24 157-162.

Castanares M, Vera Y, Erkkila K, Kyttanen S, Lue Y, Dunkel L, Wang C, Swerdloff RS \& Hikim AP 2005 Minocycline up-regulates BCL-2 levels in mitochondria and attenuates male germ cell apoptosis. Biochemical and Biophysical Research Communications 337 663-669.

Codelia VA, Cisternas P \& Moreno RD 2008 Relevance of caspase activity during apoptosis in pubertal rat spermatogenesis. Molecular Reproduction and Development 75 881-889.

Cruz AC, Frank BT, Edwards ST, Dazin PF, Peschon JJ \& Fang KC 2004 Tumor necrosis factor-alpha-converting enzyme controls surface expression of c-kit and survival of embryonic stem cell-derived mast cells. Journal of Biological Chemistry 279 5612-5620.

Diaz-Rodriguez E, Montero JC, Esparis-Ogando A, Yuste L \& Pandiella A 2002 Extracellular signal-regulated kinase phosphorylates tumor necrosis factor alpha-converting enzyme at threonine 735: a potential role in regulated shedding. Molecular Biology of the Cell 13 2031-2044.

Galan JJ, De Felici M, Buch B, Rivero MC, Segura A, Royo JL, Cruz N, Real LM \& Ruiz A 2006 Association of genetic markers within the KIT and KITLG genes with human male infertility. Human Reproduction 21 3185-3192.

Hayashi T, Kageyama Y, Ishizaka K, Xia G, Kihara K \& Oshima H 2001 Requirement of Notch 1 and its ligand jagged 2 expressions for spermatogenesis in rat and human testes. Journal of Andrology 22 999-1011.

Horiuchi K, Kimura T, Miyamoto T, Miyamoto K, Akiyama H, Takaishi H, Morioka H, Nakamura T, Okada Y, Blobel CP et al. 2009 Conditional inactivation of TACE by a Sox9 promoter leads to osteoporosis and increased granulopoiesis via dysregulation of IL-17 and G-CSF. Journal of Immunology 182 2093-2101.

Hundhausen C, Misztela D, Berkhout TA, Broadway N, Saftig P, Reiss K, Hartmann D, Fahrenholz F, Postina R, Matthews V et al. 2003 The disintegrin-like metalloproteinase ADAM10 is involved in constitutive cleavage of CX3CL1 (fractalkine) and regulates CX3CL1-mediated cell-cell adhesion. Blood 102 1186-1195.

Huovila AP, Turner AJ, Pelto-Huikko M, Karkkainen I \& Ortiz RM 2005 Shedding light on ADAM metalloproteinases. Trends in Biochemical Sciences 30 413-422. 
Jahnukainen K, Chrysis D, Hou M, Parvinen M, Eksborg S \& Soder O 2004 Increased apoptosis occurring during the first wave of spermatogenesis is stage-specific and primarily affects midpachytene spermatocytes in the rat testis. Biology of Reproduction 70 290-296.

Kassab M, Abd-Elmaksoud A \& Ali MA 2007 Localization of the epidermal growth factor (EGF) and epidermal growth factor receptor (EGFR) in the bovine testis. Journal of Molecular Histology 38 207-214.

Kim SK, Yoon YD, Park YS, Seo JT \& Kim JH 2007 Involvement of the Fas-Fas ligand system and active caspase-3 in abnormal apoptosis in human testes with maturation arrest and Sertoli cell-only syndrome. Fertility and Sterility 87 547-553.

Kissel H, Timokhina I, Hardy MP, Rothschild G, Tajima Y, Soares V, Angeles M, Whitlow SR, Manova K \& Besmer P 2000 Point mutation in kit receptor tyrosine kinase reveals essential roles for kit signaling in spermatogenesis and oogenesis without affecting other kit responses. EMBO Journal 19 1312-1326.

Levy DS, Kahana JA \& Kumar R 2009 AKT inhibitor, GSK690693, induces growth inhibition and apoptosis in acute lymphoblastic leukemia cell lines. Blood 113 1723-1729.

Lizama C, Alfaro I, Reyes JG \& Moreno RD 2007 Up-regulation of CD95 (Apo-1/Fas) is associated with spermatocyte apoptosis during the first round of spermatogenesis in the rat. Apoptosis 12 499-512.

Ludwig A, Hundhausen C, Lambert MH, Broadway N, Andrews RC, Bickett DM, Leesnitzer MA \& Becherer JD 2005 Metalloproteinase inhibitors for the disintegrin-like metalloproteinases ADAM10 and ADAM17 that differentially block constitutive and phorbol esterinducible shedding of cell surface molecules. Combinatorial Chemistry \& High Throughput Screening 8 161-171.

Mezyk-Kopec R, Bzowska M, Stalinska K, Chelmicki T, Podkalicki M, Jucha J, Kowalczyk K, Mak P \& Bereta J 2009 Identification of ADAM10 as a major TNF sheddase in ADAM17-deficient fibroblasts. Cytokine $\mathbf{4 6}$ 309-315.

Moreno RD, Lizama C, Urzua N, Vergara SP \& Reyes JG 2006a Caspase activation throughout the first wave of spermatogenesis in the rat. Cell and Tissue Research 325 533-540.

Moreno RD, Palomino J \& Schatten G 2006b Assembly of spermatid acrosome depends on microtubule organization during mammalian spermiogenesis. Developmental Biology 293 218-227.

Mullberg J, Durie FH, Otten-Evans C, Alderson MR, Rose-John S, Cosman D, Black RA \& Mohler KM 1995 A metalloprotease inhibitor blocks shedding of the IL-6 receptor and the p60 TNF receptor. Journal of Immunology 155 5198-5205.

Ortiz RJ, Lizama C, Codelia VA \& Moreno RD 2009 A molecular evaluation of germ cell death induced by etoposide in pubertal rat testes. Molecular Human Reproduction 15 363-371.

Van Pelt AMM, Morena AR, Van Dissel-Emiliani FMF, Boitani C, Gaemers CI, De Rooij DG \& Stefanini M 1996 Isolation of the synchronized A spermatogonia from adult vitamin A-deficient rat testes. Biology of Reproduction 55 439-444.

Pentikainen V, Erkkila K \& Dunkel L 1999 Fas regulates germ cell apoptosis in the human testis in vitro. American Journal of Physiology 276 E310-E316.

Perrard MH, Vigier M, Damestoy A, Chapat C, Silandre D, Rudkin BB \& Durand P 2007 beta-Nerve growth factor participates in an auto/ paracrine pathway of regulation of the meiotic differentiation of rat spermatocytes. Journal of Cellular Physiology 210 51-62.

Riccardi C \& Nicoletti I 2006 Analysis of apoptosis by propidium iodide staining and flow cytometry. Nature Protocols 1 1458-1461.

Rodriguez I, Ody C, Araki K, Garcia I \& Vassalli P 1997 An early and massive wave of germinal cell apoptosis is required for the development of functional spermatogenesis. EMBO Journal 16 2262-2270.

Ronnstrand L 2004 Signal transduction via the stem cell factor receptor/ c-kit. Cellular and Molecular Life Sciences 61 2535-2548.

Roskoski R Jr 2005 Structure and regulation of kit protein-tyrosine kinase the stem cell factor receptor. Biochemical and Biophysical Research Communications 338 1307-1315.
Sahin U, Weskamp G, Kelly K, Zhou HM, Higashiyama S, Peschon J, Hartmann D, Saftig P \& Blobel CP 2004 Distinct roles for ADAM10 and ADAM17 in ectodomain shedding of six EGFR ligands. Journal of Cell Biology 164 769-779.

Sakata S, Sakamaki K, Watanabe K, Nakamura N, Toyokuni S, Nishimune Y, Mori C \& Yonehara S 2003 Involvement of death receptor Fas in germ cell degeneration in gonads of kit-deficient $\mathrm{Wv} / \mathrm{Wv}$ mutant mice. Cell Death and Differentiation 10 676-686.

von Schonfeldt V, Wistuba J \& Schlatt S 2004 Notch-1, c-kit and GFRalpha1 are developmentally regulated markers for premeiotic germ cells. Cytogenetic and Genome Research 105 235-239.

Schulte M, Reiss K, Lettau M, Maretzky T, Ludwig A, Hartmann D, de Strooper B, Janssen O \& Saftig P 2007 ADAM10 regulates FasL cell surface expression and modulates FasL-induced cytotoxicity and activation-induced cell death. Cell Death and Differentiation $\mathbf{1 4}$ 1040-1049.

Seals DF \& Courtneidge SA 2003 The ADAMs family of metalloproteases: multidomain proteins with multiple functions. Genes and Development 17 7-30.

Skinner MK 2005 Sertoli cell-somatic cell interactions. In Sertoli Cell Biology, pp 317-329. Eds MK Skinner \& MD Grisold. San Diego: Elsevier Academic Press.

Sokal RR 1995 Biometry: the Principles and Practice of Statistics in Biological Research, pp 887. Eds RR Sokal \& J Rohlf. New York: W. H. Freeman.

Tang D, Wu D, Hirao A, Lahti JM, Liu L, Mazza B, Kidd VJ, Mak TW \& Ingram AJ 2002 ERK activation mediates cell cycle arrest and apoptosis after DNA damage independently of p53. Journal of Biological Chemistry 277 12710-12717.

Tousseyn T, Jorissen E, Reiss K \& Hartmann D 2006 (Make) stick and cut loose - disintegrin metalloproteases in development and disease. Birth Defects Research. Part C, Embryo Today 78 24-46.

Vergara S, Lizama C, Brouwer-Visser J \& Moreno RD 2010 Expression of BCL-2 family genes in germ cells undergoing apoptosis during the first wave of spermatogenesis in the rat. Andrologia [in press].

Vincent S, Segretain D, Nishikawa S, Nishikawa SI, Sage J, Cuzin F \& Rassoulzadegan M 1998 Stage-specific expression of the kit receptor and its ligand (KL) during male gametogenesis in the mouse: a kit-KL interaction critical for meiosis. Development 125 4585-4593.

Wang SE, Xiang B, Guix M, Olivares MG, Parker J, Chung CH, Pandiella A \& Arteaga CL 2008 Transforming growth factor beta engages TACE and ErbB3 to activate phosphatidylinositol-3 kinase/Akt in ErbB2overexpressing breast cancer and desensitizes cells to trastuzumab. Molecular and Cellular Biology 28 5605-5620.

Yan W, Suominen J, Samson M, Jegou B \& Toppari J 2000 Involvement of $\mathrm{BCl}-2$ family proteins in germ cell apoptosis during testicular development in the rat and pro-survival effect of stem cell factor on germ cells in vitro. Molecular and Cellular Endocrinology 165 115-129.

Yao PL, Lin YC \& Richburg JH 2009 TNFalpha-mediated disruption of spermatogenesis in response to Sertoli cell injury in rodents is partially regulated by MMP2. Biology of Reproduction 80 581-589.

Zheng S, Turner TT \& Lysiak JJ 2006 Caspase 2 activity contributes to the initial wave of germ cell apoptosis during the first round of spermatogenesis. Biology of Reproduction 74 1026-1033.

Zhengwei Y, Wreford NG \& de Kretser DM 1990 A quantitative study of spermatogenesis in the developing rat testis. Biology of Reproduction $\mathbf{4 3}$ 629-635.

Received 24 February 2010

First decision 31 March 2010

Revised manuscript received 10 May 2010

Accepted 24 May 2010 